\title{
Brunner's Gland
}

National Cancer Institute

\section{Source}

National Cancer Institute. Brunner's Gland. NCI Thesaurus. Code C13010.

Compound, tubular, submucosal glands located in the duodenum proximal to the sphincter of Oddi; these glands produce alkaline-rich secretions that function to both protect the duodenum from the acidic content of the stomach and to enable intestinal enzymes to activate, thus enabling absorption to start. 